\title{
Oxalic Acid Is an Elicitor of Plant Programmed Cell Death during Sclerotinia sclerotiorum Disease Development
}

\author{
Kyoung Su Kim, Ji-Young Min, and Martin B. Dickman \\ Institute for Plant Genomics and Biotechnology, Department of Plant Pathology and Microbiology, Texas A\&M University, \\ College Station 77843, U.S.A.
}

Submitted 3 October 2007. Accepted 19 January 2008.

\begin{abstract}
Accumulating evidence supports the idea that necrotrophic plant pathogens interact with their hosts by controlling cell death. Sclerotinia sclerotiorum is a necrotrophic ascomycete fungus with a broad host range ( $>400$ species). Previously, we established that oxalic acid (OA) is an important pathogenicity determinant of this fungus. In this report, we describe a mechanism by which oxalate contributes to the pathogenic success of this fungus; namely, that $\mathrm{OA}$ induces a programmed cell death $(\mathrm{PCD})$ response in plant tissue that is required for disease development. This response exhibits features associated with mammalian apoptosis, including DNA laddering and TUNEL reactive cells. Fungal mutants deficient in OA production are nonpathogenic, and apoptotic-like characteristics are not observed following plant inoculation. The induction of PCD by OA is independent of the pH-reducing abilities of this organic acid, which is required for sclerotial development. Moreover, oxalate also induces increased reactive oxygen species (ROS) levels in the plant, which correlate to PCD. When ROS induction is inhibited, apoptotic-like cell death induced by OA does not occur. Taken together, we show that Sclerotinia spp.-secreted $\mathrm{OA}$ is an elicitor of PCD in plants and is responsible for induction of apoptotic-like features in the plant during disease development. This PCD is essential for fungal pathogenicity and involves ROS. Thus, OA appears to function by triggering in the plant pathways responsible for PCD. Further, OA secretion by Sclerotinia spp. is not directly toxic but, more subtly, may function as a signaling molecule.
\end{abstract}

The induction of programmed cell death (PCD) in plants can be beneficial or harmful. As in animals, a programmed type of cell death occurs in plants as part of normal growth and development, including reproduction, seed germination, aerenchyma formation, tracheary element differentiation, and senescence (Filonova et al. 2002; Fukuda 2000; Lim et al. 2007; Pennell and Lamb 1997; Turner et al. 2007). Regulation of cell death pathways also occurs in response to environmental abiotic stresses (Ryerson and Heath 1996). Moreover, cell suicide programs are activated during pathogen attack that in some cases are correlated with resistance, as exemplified by the hypersensitive response (HR) which, by definition, is a form of PCD (Dangl and Jones 2001; Goodman and Novacky 1994; Heath 2000). Emerging evidence has indicated that, in

Corresponding author: M. B. Dickman; Telephone: +1.979.862.4788; Fax: +1.979.862.4790; E-mail: mbdickman@tamu.edu

* The $e$-Xtra logo stands for "electronic extra" and indicates that Figures 1 and 4 appear in color online. necrotrophic fungus-plant interactions, host cell death is beneficial for the pathogen as opposed to the plant, suggesting active involvement of the pathogen in influencing host pathways that direct cell death (Navarre and Wolpert 1999; Van Baarlen et al. 2004; Wang et al. 1996).

We have been studying pathogenic development in the broad host range necrotrophic fungus, Sclerotinia sclerotiorum (de Bary 1886). This ascomycete causes diseases in over 400 species of plants (Boland and Hall 1994). Such diseases are difficult to control genetically where breeding programs have had limited success. Management strategies, including crop rotation, are hampered due to the broad fungal host range (virtually all dicots), and spray regimes have been largely ineffective, particularly when climactic conditions are favorable to the fungus. The development of fungal sclerotia also contributes to the pathogenic success of Sclerotinia spp. Sclerotia are highly melanized and environmentally durable structures, which can overwinter and remain viable for many years in the soil. Sclerotia serve as a major source of inoculum, capable of infecting hosts through direct germination, or they can produce ascospores through apothecial development (Steadman 1979; Tourneau 1979).

Sclerotinia spp. secrete a wide array of substances to facilitate their necrotrophic life style (Annis and Goodwin 1997; Fraissinet-Tachet et al. 1995; Marciano et al. 1983; Riou et al. 1991). In addition to cell-wall-degrading enzymes, oxalic acid (OA) is known to play a key role in pathogenesis and fungal development (Godoy et al. 1990; Lumsden 1979). Oxalate-deficient mutants of $S$. sclerotiorum are nonpathogenic on all host plants tested and also are unable to develop sclerotia (Godoy et al. 1990). Oxalate secretion might enhance Sclerotinia virulence in several ways (Dutton and Evans 1996). First, many fungal enzymes secreted during invasion of plant tissues (e.g., polygalacturonase) have maximal activities at low $\mathrm{pH}$ (Bateman and Beer 1965). Consistent with the potential importance of $\mathrm{pH}$, a Sclerotinia mitogen-activated protein kinase (MAPK) was cloned, characterized, and shown to be required for sclerotial formation in S. sclerotiorum. Gene expression of this Erk-like MAPK (SMK1) is activated by acidic $\mathrm{pH}$ mediated via OA. If the $\mathrm{pH}$ is not reduced, pathogenic development does not occur (Chen et al. 2004; Rollins and Dickman 2001). Second, OA also can degrade or weaken the plant cell wall via acidity or chelation of cell wall $\mathrm{Ca}^{2+}$ (Bateman and Beer 1965). Third, OA crystals have been found in plants and can cause vascular plugging. $\mathrm{OA}$ is directly toxic, functioning as a nonspecific phytotoxin. We have shown that OA also is able to suppress the host plant oxidative burst, which is one of the earliest and most universal of plant defense responses (Cessna et al. 2000). Recently, OA has been reported to interfere with the function of guard cells, resulting in abnormal stomatal opening and inhibition of 
abscisic acid-induced stomatal closure during infection (Guimarães and Stotz 2004). Thus, it is evident that this "simple" dicarboxylic acid is used by the fungus in a number of ways when interacting with host plants. The importance of the multifunctional OA for Sclerotinia pathogenic success is underscored by the fact that OA mutants are nonpathogenic even though the fungus still maintains its full arsenal of cell-walldegrading enzymes (Godoy et al. 1990).

Previous studies have shown that injection of exogenous oxalate or application of fungal culture filtrates containing secreted oxalate mimics disease symptoms of the actual fungal infection (Bateman and Beer 1965; Noyes and Hancock 1981). However, the manner by which host cell death occurs has not been established. We have shown that transgenic tobacco expressing mammalian anti-apoptotic genes were resistant to Sclerotinia challenge (Dickman et al. 2001), suggesting that pathogenicity/cell death is an active gene-directed process. In accordance with this premise, Sclerotinia-induced disease in tobacco shares features of apoptotic-like cells in animals such as DNA fragmentation and chromatin condensation. This suggests that some components of fungal origin induce or direct PCD in plants (Dickman et al. 2001). Studies involving other host-necrotrophic pathogen systems have reported similar observations (Govrin and Levine 2000; Navarre and Wolpert 1999). Taken together, necrotrophic fungi may co-opt plant host cell death pathways to establish compatibility.

In this report, we show that Sclerotinia-secreted OA is an elicitor of PCD in plants and is responsible for induction of apoptotic-like features in the plant during disease development. This PCD is essential for fungal pathogenicity and involves reactive oxygen species (ROS). We suggest that OA functions by triggering pathways in the plant responsible for PCD. Thus, via OA, S. sclerotiorum can subvert host cell death regulatory machinery as a means to pathogenic success. Further, OA secretion by $S$. sclerotiorum is not directly toxic but may function as a signaling molecule.

\section{RESULTS}

Apoptosis-like cell death in tobacco is induced by oxalate.

Our previous study showed that inoculation of tobacco leaves with $S$. sclerotiorum resulted in disease and lesion for- mation that were preceded at the cellular level by DNA fragmentation and cleavage (DNA ladders and TUNEL positively reacting cells), features associated with apoptotic-like PCD (Dickman et al. 2001). To determine whether Sclerotinia cell extracts harbored a component or components responsible for induction of plant PCD, tobacco leaf disks and seedlings were treated with extracts from the wild-type 1980 strain or the nonpathogenic OA-deficient mutant (A-1). Both strains were cultured in $100 \mathrm{ml}$ of potato dextrose broth, $\mathrm{pH} 7.0$, and grew at equivalent rates. Significant but expected changes in $\mathrm{pH}$ in the media were noted; $\mathrm{pH} 3.35 \pm 0.13$ or $5.47 \pm 0.16$ after the 6 days of culturing 1980 or A1, respectively. OA concentrations were $4.35 \pm 0.12$ or $0.16 \pm 0.05 \mathrm{mM}$ for wild-type and mutant cultures, respectively. When plant tissue was treated with culture filtrates, DNA laddering was observed only in wild-type filtrates. When the wild-type filtrate was autoclaved, DNA laddering and disease symptoms still were evident (Fig. 1C; data not shown). These data argue against a proteinaceous compo-

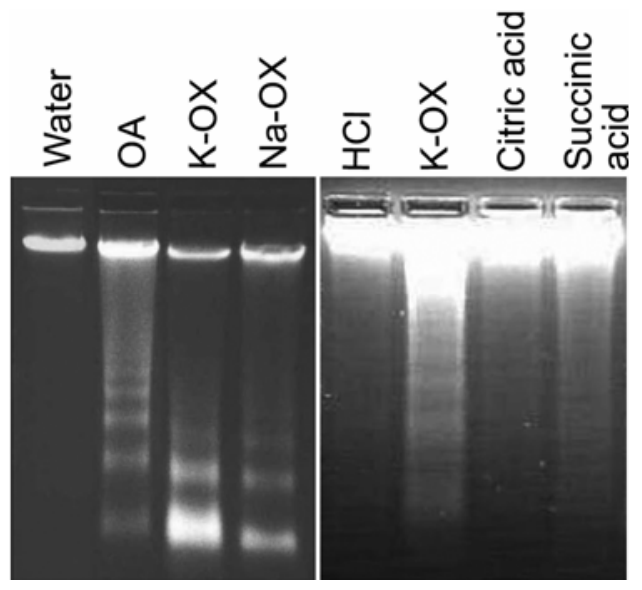

Fig. 2. Effects of oxalate formulations and other acids on DNA laddering. Tobacco leaf disks were treated with different formulations of oxalate (OX) and selected acids. These include salt-free oxalic acid (OA), sodium OX (Na-OX), potassium OX (K-OX), $\mathrm{HCl}$, citric acid, and succinic acid. Solutions used were $20 \mathrm{mM}$, except for $10 \mathrm{mM}$ of OA, and all adjusted to pH 5.0 with either $\mathrm{HCl}$ or $\mathrm{NaOH}$. Genomic DNA was extracted $36 \mathrm{~h}$ after treatment.
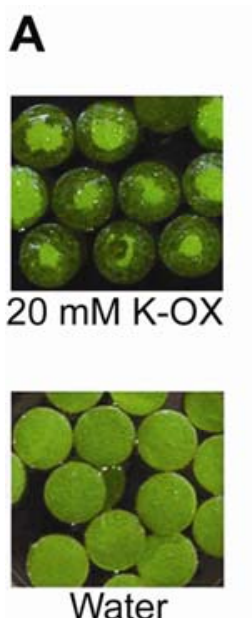

B

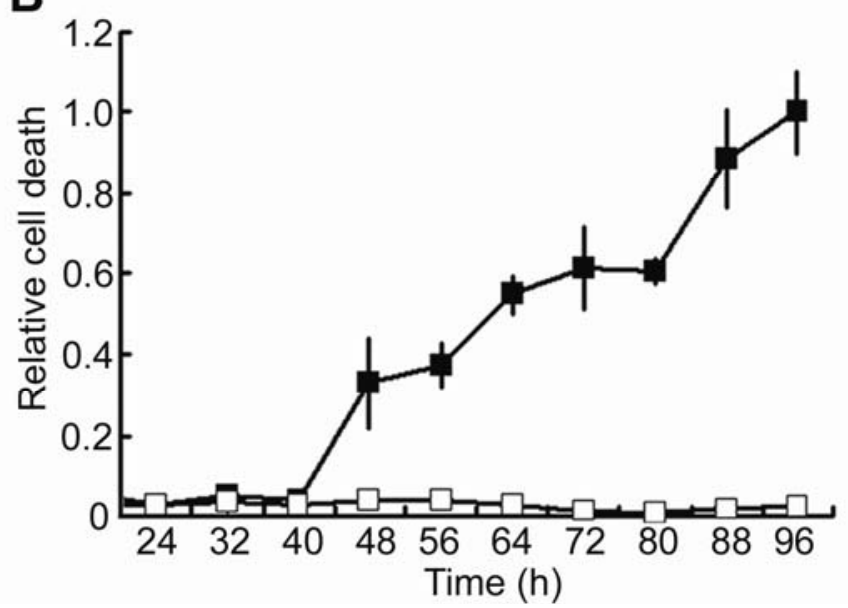

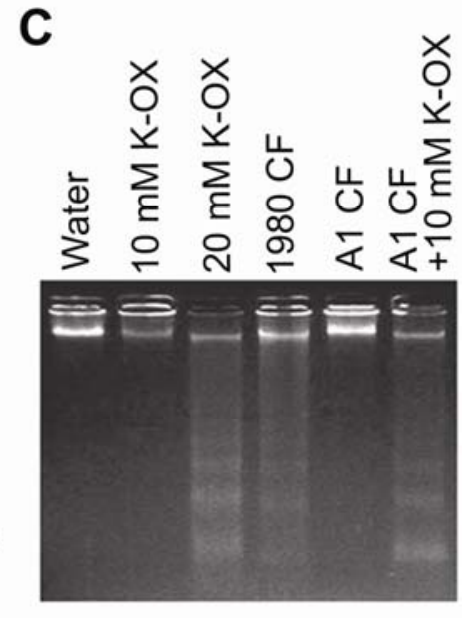

Fig. 1. Oxalate-induced cell death and DNA laddering in tobacco leaf disks. A, Macroscopic symptoms of tobacco leaf disks treated with 20 mM potassium oxalate (K-OX, pH 7.0) or water (as a control) for 72 h. B, Time course of cell death following K-oxalate (20 mM, pH 7.0$)$ treatment. Cell death in tobacco leaf disks was determined using Evans blue staining. Dye released from dead cells was measured at absorbance at 600 nm. Measurements were expressed as relative values with 1 corresponding to the maximum of a sample. Data are presented as means \pm standard deviation from three independent experiments. $\mathbf{C}$, DNA fragmentation in tobacco leaf disks $36 \mathrm{~h}$ after treatment with K-OX (10 or $20 \mathrm{mM}$, pH 7.0) and autoclaved culture filtrates (CF) from a wild-type (1980) or an oxalate-defective mutant (A1) of Sclerotinia sclerotiorum. 
nent from the filtrate being responsible for cell-death-inducing activity. Therefore, we focused our attention on an obvious candidate, OA.

Based on our preliminary data and previous research (Cessna et al. 2000), tobacco leaf disks were treated with potassium oxalate (K-OX), pH 7.0. Water-soaked lesions developed in leaf disks treated with $20 \mathrm{mM} \mathrm{K-OX}$ after $72 \mathrm{~h}$ (Fig. 1A). In addition, seedling treatment showed a similar response with respect to DNA laddering and disease symptoms at $5 \mathrm{mM}$ K-OX (data not shown). Quantitative and time-course analysis of cell death in tobacco leaf disks was measured using Evans blue staining (Fig. 1B). No significant difference in cell viability was observed in the treatment of K-OX and water until $48 \mathrm{~h}$ after treatment was initiated. However, from 48 through $96 \mathrm{~h}$, substantial increases in cell death were observed in oxalatetreated leaf disks. By 96 h, extensive cell death and tissue collapse occurred. Lower concentrations of oxalate (e.g., $10 \mathrm{mM}$ ) yielded similar but delayed results (data not shown). Thus, oxalate induced plant cell death in a dose- and time-dependent manner. Based on the kinetics of the cell death in response to oxalate, tobacco DNA was isolated at several time points. DNA cleavage resulting in a characteristic DNA laddering pattern associated with apoptotic cell death was observed (Fig. 1C). DNA laddering was detected in the oxalate treatment before macroscopic symptoms were observed. DNA fragmentation appears to be specific to OA because other acids such as citric acid, succinic acid, and hydrochloric acid did not yield DNA ladders (Fig. 2). DNA cleavage also was independent of oxalate formulation because OA, potassium oxalate, and sodium oxalate all caused DNA laddering (Fig. 2), thus suggesting that PCD induction is not due to the acidic nature of oxalate but rather to a property of oxalate itself. Further, the addition of $10 \mathrm{mM} \mathrm{K-OX,} \mathrm{pH} 7.0$, to the A1 culture filtrate induced DNA laddering (Fig. 1C). When tomato leaves were pretreated with $20 \mathrm{mM} \mathrm{K-OX}$, the A-1 mutant showed a partial restoration of the disease phenotype (data not shown). Taken together, fungal-secreted oxalate is responsible for the induction apoptotic-like PCD in tobacco.

\section{Effects of pH and light \\ on oxalate-induced cell death in tobacco.}

$\mathrm{pH}$ is an important factor in Sclerotinia pathogenesis (Chen et al. 2004; Dickman 2007). To further evaluate the effect of $\mathrm{pH}$ on oxalate-induced cell death, we compared the effects of various $\mathrm{pHs}$ with respect to the level of oxalate-mediated cell death (Fig. 3). Leaf disks were treated with K-OX adjusted to pHs 3 to 6 with $\mathrm{HCl}$. pH clearly had an effect on symptoms (Fig. 3A) because $\mathrm{pH} 3$ conditions caused extensive yellowing and water soaking of the plant tissue; pH 5 and 6 showed milder symptoms but tissue death was evident. Importantly, DNA laddering was observed only at $\mathrm{pH} 5$ and 6 , not at $\mathrm{pH} 3$ or 4 (Fig. 3B). Na-citrate, which is similar to oxalate in its ability to modulate $\mathrm{pH}$ and chelate calcium and inhibit the plant oxidative burst (Cessna et al. 2000), also was used as a control. No DNA laddering was observed at any of the $\mathrm{pH}$ conditions used. These observations are consistent with a specific induction of plant PCD by oxalate that is independent of its acidic $\mathrm{pH}(\leq 4.0)$ regulatory properties.

It has been reported that light often is required for PCD (Chen and Dickman 2004; Samuilov et al. 2002, 2003). To determine whether or not light is necessary for oxalate-induced cell death, oxalate-treated leaf disks were incubated under fluorescent light at room temperature or in the dark for $48 \mathrm{~h}$ (Fig. 3C). Cell death under both light and dark conditions was induced significantly compared with the control. However, a greater proportion of cells died under dark conditions than under lighted conditions. These results suggest that dark con- ditions may augment oxalate-induced cell death of tobacco plants or that light has an inhibitory effect.

\section{ROS are involved in oxalate-induced cell death.}

The generation of ROS (e.g., hydrogen peroxide and superoxide) is well documented as one the earliest and most universal responses of plants to biotic stress. A frequent outcome of this controlled response is a PCD that often is correlated with plant resistance, commonly known as the HR. Oxidative stress is also a trigger of PCD in mammals (Nakazato et al. 2007). In plants, oxidative stress has been shown to induce apoptoticlike features, including DNA laddering, chromatin condensation, and cell shrinkage (Heath 2000; Houot et al. 2001). ROS regulation also been implicated as a developmental signal and is involved with regulating pathogenicity in several fungi (Egan et al. 2007; Leuthner et al. 2005; Tanaka et al. 2006). Therefore, we were interested in determining whether ROS was involved in Sclerotinia disease development and, more specifically, as it relates to PCD. Leaf disks were treated with $\mathrm{K}-\mathrm{OX}$ for $24 \mathrm{~h}$, then stained for with 3'3-diaminobenzidine (DAB), which commonly is used to detect $\mathrm{H}_{2} \mathrm{O}_{2}$ (ThordalChristensen et al. 1997). All leaf disks had a ring of lightly stained material at the periphery, presumably as a result of wounding (Fig. 4A). However, K-OX-treated leaf disks were

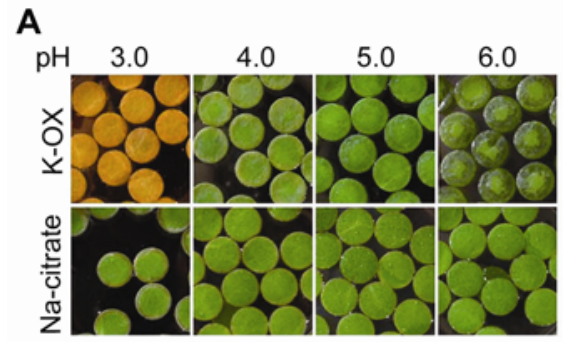

B

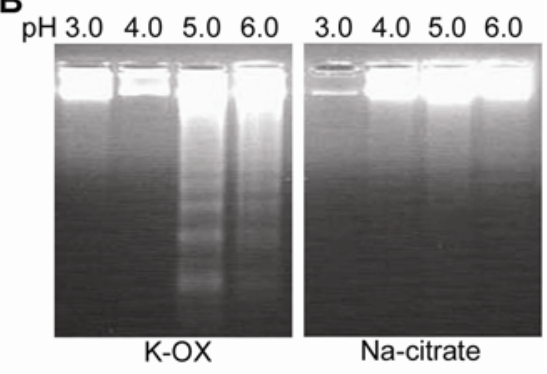

C

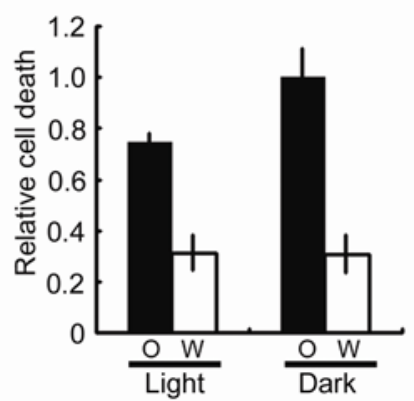

Fig. 3. Effect of $\mathrm{pH}$ and light on potassium oxalate (K-OX)-induced cell death in tobacco leaf disks. A, Macroscopic symptoms of tobacco leaf disks incubated with different pHs of K-OX (20 mM) and Na-citrate (5 $\mathrm{mM}) . \mathrm{HCl}$ was used to adjust the $\mathrm{pH}$. B, $\mathrm{pH}$ effects on K-OX-induced DNA laddering in leaf disks. DNA was extracted from tested disks in A. C, Light and dark effects on K-OX-induced plant cell death. Leaf disks were incubated at room temperature either under fluorescent light or dark condition with K-OX $(\mathrm{O}, 20 \mathrm{mM}$, pH 5.0) or water (W, pH 5.0). Cell death was measured using Evans blue staining $40 \mathrm{~h}$ after treatment. Data are presented as means \pm standard deviation from three independent experiments. 
heavily stained throughout and clearly distinct from the control disk. The intensity of staining also was dose and $\mathrm{pH}$ dependent (Fig. 4A and B). Tobacco leaf disks were treated with K-OX adjusted to $\mathrm{pH} 3$ to 6 for $24 \mathrm{~h}$. Leaf disks treated at $\mathrm{pH} 5$ and 6 were positively stained by DAB; disks at $\mathrm{pH} 3$ and 4 were not (Fig. 4B). Oxalate-induced PCD, as we have shown, occurs at relatively higher $\mathrm{pH}$ (5 to 6 ), and was not observed at acidic $\mathrm{pH}$ (3 to 4$)$. Thus, the observation that there was no ROS detected at acidic $\mathrm{pH}$ coincided with the lack of PCD. At the higher pHs where DNA laddering occurred, ROS increases were correspondingly evident. Thus, there was a very good relationship between the ROS levels and the ability of oxalate to induce PCD.

We examined the ROS detoxification enzymes superoxide dismutase (SOD), which dismutates superoxide to $\mathrm{H}_{2} \mathrm{O}_{2}$, and catalase, which converts $\mathrm{H}_{2} \mathrm{O}_{2}$ to water, for effects on OA-

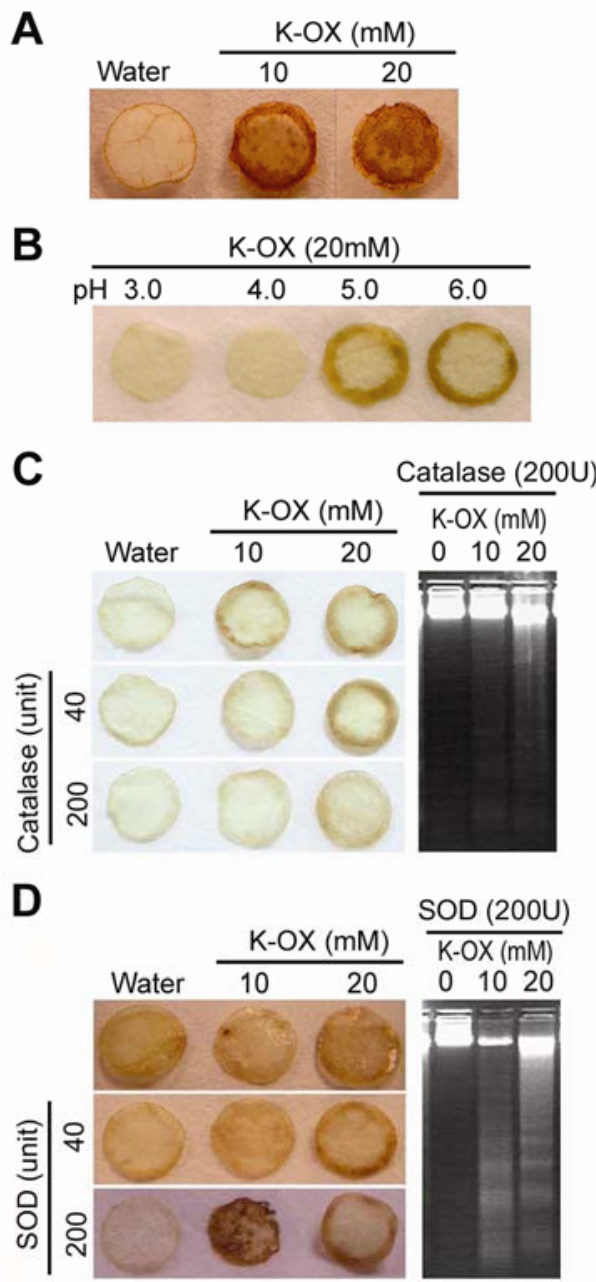

Fig. 4. Involvement of reactive oxygen species (ROS) in potassium oxalate (K-OX)-induced cell death in tobacco leaf disks. A, In situ detection of $\mathrm{H}_{2} \mathrm{O}_{2}$ in leaf disks treated with $\mathrm{K}-\mathrm{OX}\left(\mathrm{pH}\right.$ 7.0). $\mathrm{H}_{2} \mathrm{O}_{2}$ production was visualized by $3,3^{\prime}$-diaminobenzidine (DAB) staining. $\mathrm{H}_{2} \mathrm{O}_{2}$ production (revealed by reddish-brown stain) was detected $24 \mathrm{~h}$ after K-OX treatment. B, Effect of $\mathrm{pH}$ of K-OX on ROS generation in leaf disks. Disks were treated in a different $\mathrm{pH}$ of $\mathrm{K}-\mathrm{OX}(20 \mathrm{mM})$ adjusted with $\mathrm{HCl}$. Tested disks were stained after $24 \mathrm{~h}$. C, Effect of catalase on $\mathrm{H}_{2} \mathrm{O}_{2}$ production and programmed cell death (PCD). Leaf disks were co-treated for $24 \mathrm{~h}$ in a combination of K-OX (10 or $20 \mathrm{mM}$, pH 7.0) with catalase (40 or 200 units), after which disks were stained with DAB or used for DNA extraction. D, Effect of superoxide dismutase (SOD) on $\mathrm{H}_{2} \mathrm{O}_{2}$ production and PCD. Leaf disks were co-treated for $24 \mathrm{~h}$ in a combination of K-OX (10 or $20 \mathrm{mM}$, $\mathrm{pH} 7.0$ ) with SOD (40 or 200 units), after which disks either were stained with DAB or used for DNA extraction. induced PCD. Leaf disks were treated simultaneously with catalase or SOD with K-OX, pH 5.5, and stained with DAB 24 $\mathrm{h}$ post treatment, which was prior to the appearance of watersoaked lesions. $\mathrm{H}_{2} \mathrm{O}_{2}$ generation was inhibited by catalase (40 units for $10 \mathrm{mM}$ and 200 units for $20 \mathrm{mM}$ of K-OX) (Fig. 4C). However, SOD did not reduce $\mathrm{H}_{2} \mathrm{O}_{2}$ generation in co-treatment with $\mathrm{K}-\mathrm{OX}$ and actually enhanced $\mathrm{H}_{2} \mathrm{O}_{2}$ levels in the higher SOD treatment (Fig. 4D). Because SOD increases $\mathrm{H}_{2} \mathrm{O}_{2}$ levels, this result was not entirely unexpected. Consistent with these observations, the induction of DNA ladders in these treatments showed that catalase inhibited DNA laddering and SOD did not (Fig. 4C and D). Thus, K-OX generates $\mathrm{H}_{2} \mathrm{O}_{2}$ that is catalase but not SOD inhibitable. $\mathrm{H}_{2} \mathrm{O}_{2}$ generation also is required for DNA ladder formation indicative of PCD.

\section{Application of antioxidants or expression of CED-9 prevents OA-induced PCD in tobacco.}

Our data suggested that $S$. sclerotiorum-induced plant disease involved the activation of pathways culminating in PCD. To gain insight into the pathways or pathway components mediating $S$. sclerotiorum (OA)-induced plant $\mathrm{PCD}$, various reagents, including the protease inhibitor E-64, antioxidants $\mathrm{N}$ acetyl cysteine (NAC) and diphenyleneiodonium (DPI), calcium influx blockers lanthanum chloride $\left(\mathrm{LaCl}_{3}\right)$ and verapamil, the catalase inhibitor 3-aminotriazole (3-AT), the de novo protein synthesis inhibitor cycloheximde, and the serine/threonine protein kinase inhibitor $\mathrm{K}-252 \mathrm{a}$, were used to treat tobacco leaf disks with or without K-oxalate treatment to evaluate effects on oxalate-induced PCD. DNA ladder formation was used as a readout because there was a consistent correlation with DNA laddering, cell death, and lesion formation. At the concentrations used, none of the chemicals alone induced cell death. DPI, an inhibitor of NADPH oxidase (which generates superoxide), prevented DNA laddering induced by both 10 and 20 mM K-OX (Fig. 5A). NAC was less effective, as was E-64, a cysteine protease inhibitor. 3-AT had no effect on inhibition of oxalate-induced DNA laddering, as expected. (The difference in laddering observed in the $10 \mathrm{mM} \mathrm{K-OX}$ treatments between Figure $1 \mathrm{C}$ and Figure 5A is attributed to increased DNA concentration in Figure 5A.) Measurement of oxalate-induced cell death using Evans blue staining was consistent with the DPI results; DPI significantly prevented plant cell death (Fig. 5B), suggesting the involvement of an NADPH oxidase in the induction of PCD. Co-treatment with verapamil, cycloheximide, or $\mathrm{K}-252 \mathrm{a}$ and, to a lesser extent, $\mathrm{LaCl}_{3}$ had little effects on oxalate-induced cell death, suggesting that oxalate-induced cell death may not require calcium ion channel activity, de novo protein synthesis, or general serine/threonine protein kinase activity.

Previous studies described the generation of transgenic tobacco plants expressing negative regulators of mammalian apoptosis and resistance to Sclerotinia spp. challenge (Dickman et al. 2001). Because oxalate is an elicitor of cell death in tobacco plants, we tested the response of CED-9 expressing transgenic tobacco to oxalate. CED-9 is a Bcl-2 family member from the nematode Caenorhabditis elegans, and is a wellcharacterized inhibitor of developmental PCD in the worm (Hengartner and Horvitz 1994). In transgenic tobacco expressing CED-9, cell death was reduced dramatically (Fig. 5B), consistent with our previous data showing increased disease resistance.

\section{DISCUSSION}

PCD is a major process by which eukaryotes regulate normal growth and development as well as stress responses (Vaux and Strasser 1996). Accumulating evidence shows that inap- 
propriate regulation of $\mathrm{PCD}$ can have dire consequences for an organism. In humans, cancer can be promoted when PCD does not occur when it normally should. Alternatively, Parkinson's and neurological disorders are observed when cell death occurs when it should not. Thus, the potential benefits of a given PCD regime are clearly context dependent. In plant-pathogen interactions, PCD historically has been associated with plant resistance via the HR. The HR and subsequent cell death have been correlated with the accumulation of ROS during the oxidative burst (Jabs 1999). By definition, the HR is a programmed death and shares characteristics of mammalian apoptosis (Dickman and Reed 2003; Heath 2000).

In this report, we show that OA, a key determinant of pathogenicity for the necrotrophic fungal phytopathogen $S$. sclerotiorum, uses oxalate to elicit an apoptosis-like PCD in tobacco, and the induction of this fungal-mediated plant cell death process is required for pathogenic success. Thus, OA, a nonspecific phytotoxin at levels found in plant tissue, does not appear to be directly toxic but rather functions as a signaling molecule or elicitor to subvert and redirect host pathways toward cell death. Our data also indicate that ROS are involved in the $S$. sclerotiorum interaction with host plants. ROS also have been considered detrimental to cells because they can be toxic, causing damage to proteins, lipids (membranes), and nucleic acids. However, it is now evident that low concentrations of ROS have a beneficial function as regulatory molecules in cell-signaling pathways. By virtue of their diffusibility, controlled production, and regulation, ROS, particularly $\mathrm{H}_{2} \mathrm{O}_{2}$, can function as second messengers, suggesting that intra- and intercellular signaling within the pathogen and during host-pathogen crosstalk are key components dictating the eventual outcome of this interaction. Moreover, our data are consistent with the premise that necrotrophic plant pathogens interact with their hosts in a manner much more subtly than perhaps originally considered, and that the success of necrotrophs as pathogens may not be simply attributed to "brute force" via degradative enzymes or toxins. Consistent with this idea is the observation that the Cochliobolus victoriae host-selective toxin victorin does not directly kill plant cells but induces an apoptotic-like cell death in oat as well as inducing "defense" responses (Navarre and Wolpert 1999; Tada et al. 2001; Yao et al. 2001).

Additionally, ROS has a role in plant-fungus mutualistic associations. Epichloe festucae requires fungal-generated ROS to regulate its mutualistic symbiosis with perennial ryegrass (Tanaka et al. 2006). In a REMI screen to identify genes needed for symbiosis, a fungal NADPH oxidase (noxA) knockout was found that not only resulted in the loss of mutualism but also, interestingly, pathogenicity ensued. Deletion of the second fungal E. festucae nox gene had no such effect. ROS accumulation was detected at the interface between the two partners in wild-type but not mutant associations, indicating that fungal ROS production is necessary for maintenance of mutualism and, possibly, prevention of runaway cell death (Jabs et al. 1996).

The broad host range necrotrophic fungus Botrytis cinerea also modulates the redox environment during pathogenesis (Unger et al. 2005; Van Baarlen et al. 2004). Work in the laboratory of Tudzynski and colleagues has shown that a deletion mutant of a $B$. cinerea $\mathrm{Cu} / \mathrm{Zn}$ SOD resulted in a significant reduction in lesion formation on bean leaves. A similar knockout mutant of a glucose oxidase gene showed no effect on virulence. Because both enzymes can generate $\mathrm{H}_{2} \mathrm{O}_{2}$, the specific importance of the SOD was demonstrated (Rolke et al. 2004). These data also suggest the importance of ROS generation for necrotrophic fungal virulence. The same group also characterized a transcription factor (CPTF1) from Claviceps pupurea, which is responsive to and responsible for cellular redox status. Knockouts of CPTF1 were reduced in virulence and no longer responsive to oxidative stress in the knockout mutant strain (Nathues et al. 2004). Of relevance to our work was the observation that mutant inoculated plants had significant amounts of $\mathrm{H}_{2} \mathrm{O}_{2}$, which was not observed in wild-type inoculations. Thus, Claviceps redox regulation in the context of host-fungus interactions may have a dual function: inducing ROS for disease development and regulating the plant oxidative burst defense response. This dual regulation of both the fungal and host redox environment by the pathogen is consistent with observations we have made in S. sclerotiorum.

\section{Oxalate suppresses the host plant oxidative burst.}

The oxidative burst, the controlled release of $\mathrm{O}_{2}^{-}$and $\mathrm{H}_{2} \mathrm{O}_{2}$, is one of the earliest and most universal responses observed in plants following pathogen challenge (Apel and Hirt 2004; Bolwell 1999; Torres et al. 1998). Such responses occur in
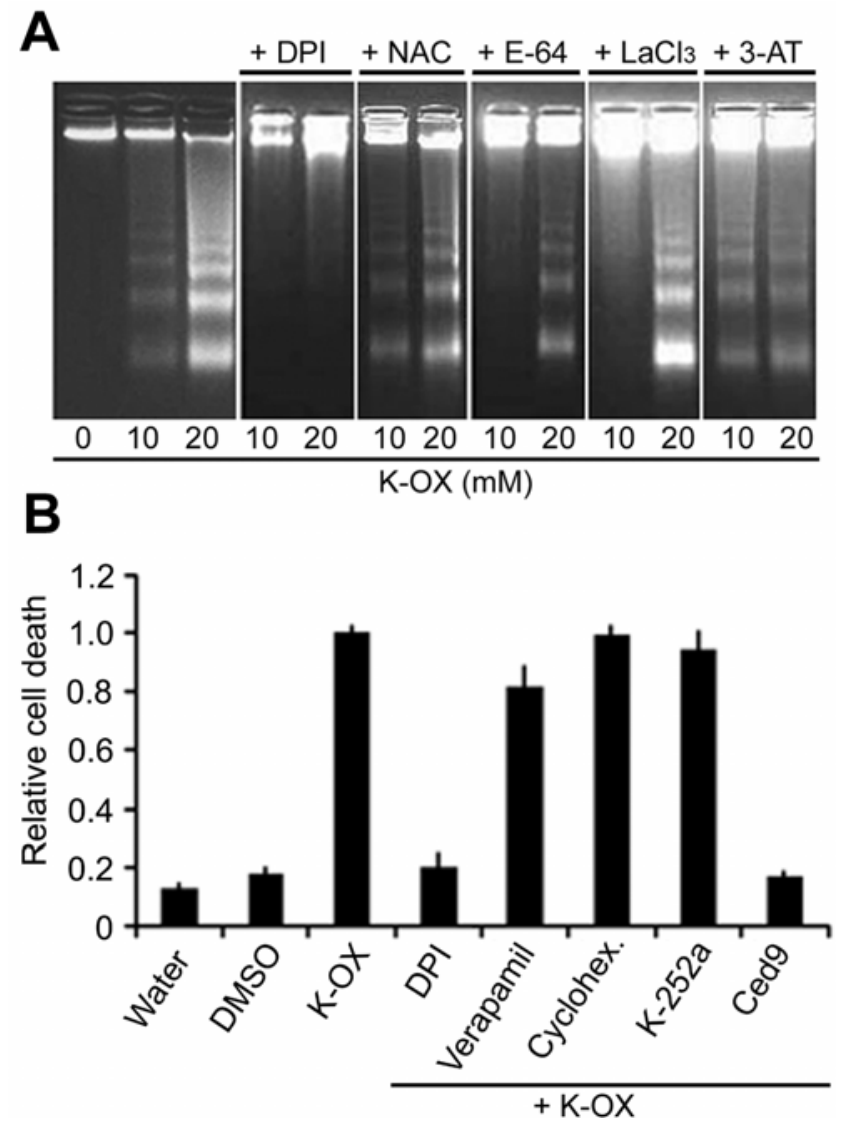

Fig. 5. Effect of selected reagents on oxalate-induced programmed cell death (PCD). A, Effects of various reagents on potassium oxalate (K-OX)induced PCD in tobacco leaf disks. DNA was extracted from tissues coincubated in a solution of K-OX (10 or $20 \mathrm{mM}, \mathrm{pH} 7.0)$ with or without reagents, including diphenyleneiodonium (DPI) $(100 \mu \mathrm{M})$, N-acetyl cysteine (NAC) $(100 \mu \mathrm{M})$, E-64 $(100 \mu \mathrm{M})$, lanthanum chloride $\left(\mathrm{LaCl}_{3}\right)$ $(10 \mathrm{nM})$, or 3-aminotriazole (3-AT) $(2 \mathrm{nM})$. DNA was isolated from tissues after treatment for $36 \mathrm{~h}$. B, Effect of various reagents on K-OXtreated wild-type and ced9-transgenic tobacco leaf disks. Wild-type tobacco disks were incubated with K-OX $(20 \mathrm{mM}, \mathrm{pH} 7.0)$ with or without inhibitors, including DPI $(100 \mu \mathrm{M})$, verapamil $(200 \mu \mathrm{M})$, cycloheximide $(2 \mu \mathrm{M})$, or $\mathrm{K}-252 \mathrm{a}(2 \mu \mathrm{M})$. Transgenic tobacco disks expressing CED-9 were treated with K-OX $(20 \mathrm{mM})$. Solutions of $2 \%$ dimethyl sulfoxide (DMSO) or water alone served as controls. Cell death was determined by Evans blue staining after $48 \mathrm{~h}$ of treatment. Spectrophotometric measurement at absorbance at $600 \mathrm{~nm}$ was expressed as relative values, with 1 corresponding to the maximum of a sample. Data are presented as means \pm standard deviation from three independent experiments, each of which contained pooled disks. 
both compatible and incompatible responses, although the timing and magnitude may differ. The oxidative burst also occurs during plant development (Foreman et al. 2003) and is expressed in most if not all plant species (Bolwell 1999). The oxidative burst also is known to be suppressed at low pH (Legendre et al. 1993). Because release of oxalate could lower the $\mathrm{pH}$, we hypothesized that OA might enhance fungal pathogenicity by inhibiting or dampening the oxidative burst of the host plant. In biochemical studies, we showed this to be the case both in vitro and in vivo (Cessna et al. 2000). The nonpathogenic $\mathrm{OA}^{-}$ mutants were unable to inhibit plant ROS induction. Importantly, oxalate blocked the oxidative burst even at the optimal $\mathrm{pH}$ of the pathway. These data revealed a previously unrecognized function of oxalate secretion by Sclerotinia spp.; namely, to suppress ROS generation and, thereby, compromise plant defense responses. We show that OA and Sclerotinia spp. increase ROS levels in the plant and induce DNA laddering and TUNEL positively reacting cells, all of which are hallmarks of apoptotic-like cell death. Thus, OA appears to be central to ROS signaling, causing a programmed-like cell death of the host, which is consistent with necrotrophy.

Oxalate-induced ROS production and PCD activities also correlate with $\mathrm{pH}$. Oxalate induces $\mathrm{PCD}$ together with positive $\mathrm{DAB}$ staining at higher $\mathrm{pH}$ (5 to 6); these features are not observed at relatively acidic conditions ( $\mathrm{pH} 3$ to 4), although cell death occurs. Moreover, when cells are co-treated with OA and DPI, not only are ROS diminished but DNA laddering also is abolished and lesion formation is not observed. Thus, there is an apparent dual ROS regulatory scheme occurring: S. sclerotiorum downregulates the plant oxidative burst via OA, possibly in a pH-independent fashion (Cessna et al. 2000); while also generating ROS in a $\mathrm{pH}$-dependent manner, which is necessary for inducing PCD pathways. A key question is: how does the fungus suppress the ROS production involved in the plant defense response on the one hand while similarly inducing ROS to promote compatibility? Possibly, there are temporal differences in $\mathrm{OA}$ and consequent $\mathrm{pH}$ changes that occur during pathogen ingress into host tissue; in the early stages, ROS and PCD are triggered by low levels of OA at relatively high $\mathrm{pH}(>5)$. As OA accumulates, the $\mathrm{pH}$ is lowered and the interaction becomes more necrotic in nature, which is accompanied by suppression of ROS and PCD, enabling the pathogen further ingress into plant tissue.

We used chemical treatments as a first pass to gain insight into the players and pathways mediating PCD. E-64, a cysteine protease inhibitor, partially blocked $\mathrm{PCD}$, as did $\mathrm{LaCl}_{3}$, a calcium channel blocker. DPI effectively inhibited DNA laddering and cell death in oxalate-treated leaf disks, suggesting the involvement of an NADPH oxidase-mediated ROS during the fungus-induced PCD. Conversely, 3-AT, a catalase inhibitor, exhibited no inhibitory abilities of this type, as expected (Fig. 5). Similar observations also were noted in B. elliptica-induced PCD (Van Baarlen et al. 2004).

\section{OA is multifunctional and an elicitor of plant PCD.}

For many years, OA has been known as a key determinant in Sclerotinia pathogenicity, initially because OA was found in high concentrations $(>10 \mathrm{mM})$ in diseased plant tissue. Accordingly, this correlation led to speculation as to how OA secretion might enhance Sclerotinia virulence (Dutton and Evans 1996). We have added to this expanding list of functions that this relatively simple dicarboxylic acid can perform. The ability of OA to downregulate the plant oxidative burst has been discussed. We also have established OA involvement in pathogenic development during sclerotium formation. $\mathrm{OA}^{-}$mutants do not form sclerotia (Godoy et al. 1990). The Sclerotinia Erk-like MAPK (encoded by smk-1) is activated by OA via reduction in $\mathrm{pH}$ (Chen et al. 2004). If the $\mathrm{pH}$ is buffered and acidification does not occur, sclerotia do not form (Rollins and Dickman 2001).

Previously, we showed that expression of selected mammalian inhibitors of apoptosis protected tobacco plants from infection by Sclerotinia spp., suggesting that a PCD might be induced in the plant by the fungus. Consistent with this idea was the additional observation that, during fungal infection of wild-type susceptible tobacco, DNA laddering and TUNEL positive-reacting plant cells were observed. Our conclusion was that $S$. sclerotiorum was hijacking plant machinery to induce PCD. The initial basis for the work presented here was to identify the molecules responsible for cell death induction. Fungal extracts induced DNA ladders, lesion formation, and cell death when tobacco leaf tissue was treated with these extracts. Boiled or autoclaved extracts gave identical results, thus indicating that the responsible party was not likely to be a protein. Although we cannot exclude unknown heat-stable nonproteinaceous factors being responsible for PCD activity, several lines of evidence were consistent with OA being the specific elicitor of plant PCD: i) addition of OA in several formulations induced DNA laddering and lesion formation in a time- and dose-dependent manner; ii) OA-deficient nonpathogenic mutant culture filtrates did not exhibit laddering; however, laddering was restored when OA was exogenously supplied; and iii) other organic acids at similar concentrations were unable to induce ladders. Consistent with these observations is the fact that OA-induced PCD is not induced at acidic $\mathrm{pH}$ (3 to 4) but rather at $\mathrm{pH} 5$ and 6. Low $\mathrm{pH}$ can cause cell death but it does not appear to be programmed and, presumably, is a necrotic type of death. Thus, OA-induced PCD is not due to $\mathrm{pH}$ signaling as we have shown to be operative during sclerotial development in Sclerotinia spp. via OA-activated MAPK (Chen et al. 2004). Thus, some other property of oxalate is responsible for its ability to induce PCD.

Oxidative stress signaling is a key component of plant and fungal development as well as plant stress responses and PCD, and appears to be induced by oxalate. When tobacco leaf disks were treated with K-OX under conditions that cause PCD (as evidenced by tissue death and ladder formation) followed by DAB staining for $\mathrm{H}_{2} \mathrm{O}_{2}$, plant tissue was positively stained, indicative for ROS production. Consistent with the presence of $\mathrm{H}_{2} \mathrm{O}_{2}$ is the observation that catalase significantly blocked staining and disease whereas SOD treatment of plant tissues had negligible and, in some cases, enhanced effects. Moreover, DNA laddering was inhibited by catalase but not by SOD. When K-OX-treated tissues were treated with DPI not only were ROS diminished but DNA laddering (indicative of cell death) also was abolished. Oxalate is a substrate for the germin family of plant proteins, which are found in many plant species (Lane et al. 1993). Germins have oxalate oxidase activity resulting in the conversion of oxalate to $\mathrm{H}_{2} \mathrm{O}_{2}$ The production of $\mathrm{H}_{2} \mathrm{O}_{2}$ by oxalate oxidase has been proposed to play a role in plant defenses against biotic and abiotic stresses (Berna and Bernier 1999; Hurkman et al. 1994). Moreover, transgenic dicot plants (soybean and sunflower) expressing a monocot oxalate oxidase gene showed increased resistance to Sclerotinia spp. This could explain why $S$. sclerotiorum is restricted to dicot hosts, which do not appear to have oxalate oxidase activity (Cober et al. 2003; Hu et al. 2003). We are currently exploring this possibility.

We conclude that $S$. sclerotiorum-secreted oxalate induces ROS in the plant host that appears to trigger a PCD pathway, resulting in plant cell death and the generation of a suitable environmental niche for fungal pathogenic development, nutrient acquisition, and the establishment of a necrotrophic relationship. Thus, for a number of plant-pathogen interactions, 
the outcome of disease versus resistance is dependent on which partner is in control of the cell death process.

\section{MATERIALS AND METHODS}

\section{Plant and fungal materials.}

S. sclerotiorum isolate 1980 and an oxalate-deficient mutant (A-1) of this strain were maintained at $24^{\circ} \mathrm{C}$ on potato dextrose agar as previously described (Godoy et al. 1990). The culture filtrates of Sclerotinia isolates were obtained from 6-day-old growth of mycelia in $100 \mathrm{ml}$ of potato dextrose broth at $24^{\circ} \mathrm{C}$. The cultures were filtered through miracloth (Calbiochem, San Diego, CA, U.S.A.).

Wild-type and transgenic tobacco (Nicotiana tabacum cv. Glurk) expressing the nematode $C E D-9$ gene were grown from seed in a growth room at $25^{\circ} \mathrm{C}$ with 16 -h light periods as previously described (Dickman et al. 2001). Leaf disks were obtained from 7-week-old plants using a 10-mm-diameter cork borer (Boekel Scientific, Feasterville, PA, U.S.A.). Leaf disks were vacuum infiltrated for $3 \mathrm{~min}$ in oxalate solutions and placed under fluorescent lights at room temperature. For dark growth conditions and inhibitor assays, plates containing tested disks were wrapped with foil and placed at room temperature.

\section{OA measurement.}

Culture filtrates of strains 1980 or A-1 were centrifuged at $1,500 \times g$ for $10 \mathrm{~min}$, discarding the pellet. The concentration of OA was determined using an oxalate detection kit according to the manufacturer's instructions (Sigma-Aldrich, St. Louis) and a standard curve using potassium oxalate. Each experiment was performed twice in duplicate. Values were presented as means \pm standard deviation of experiments.

\section{Chemicals.}

All reagents were purchased from Sigma-Aldrich or Calbiochem. Chemicals were solubilized in water or dimethyl sulfoxide. An equivalent amount of dimethyl sulfoxide was used as a control.

\section{Measurement of cell death.}

Cell death was determined and quantified by using Evans blue. Cell membranes are permeable and, thus, stained when cell death occurs (Baker and Mock 1994). Briefly, treated leaf disks were submerged in $0.25 \%$ (wt/vol) Evans blue solution (MP Biomedicals, Santa Anna, CA, U.S.A.) for $20 \mathrm{~min}$. Excess and unbound dye was removed with deionized water. The disks were placed in liquid nitrogen, homogenized, placed in $1 \%$ (wt/vol) sodium dodecyl sulfate (SDS) solution, and incubated for $10 \mathrm{~min}$ at $37^{\circ} \mathrm{C}$. Solutions were centrifuged at $13,000 \times g$ for $5 \mathrm{~min}$. The quantity of remaining dye was spectrophotometrically measured at $600 \mathrm{~nm}$. Measurements were expressed as relative values, with 1 corresponding to a maximum of a sample tested.

For the detection of DNA laddering, total plant DNA was extracted using a modified method (Ryerson and Heath 1996). Leaf disks were homogenized using liquid nitrogen. Samples were incubated for $30 \mathrm{~min}$ at room temperature in DNA extraction buffer $(0.1 \mathrm{M}$ glycine, $50 \mathrm{mM} \mathrm{NaCl}, 10 \mathrm{mM}$ EDTA, $2 \%$ SDS, and $1 \%$ sodium lauryl sarcosine) and mixed with an equal volume of Tris-saturated phenol. The mixture was centrifuged for $15 \mathrm{~min}$ at $10,000 \times g$. The supernatant was treated with chloroform/isoamyl alcohol (24:1, vol/vol). After centrifugation as above, DNA was precipitated with a twofold volume of $100 \%$ ethanol, washed with $70 \%$ ethanol, and dissolved in Tris-EDTA buffer containing RNase A $(40 \mu \mathrm{g} / \mathrm{ml})$. DNA was recovered after phenol extraction and ethanol pre- cipitation. DNA samples were separated on a $1.5 \%$ agarose gel in $0.5 \times$ Tris-borate-EDTA $\left(1 \times 89 \mathrm{mM}\right.$ Tris, $89 \mathrm{mM} \mathrm{H}_{3} \mathrm{BO}_{3}$, and $2 \mathrm{mM}$ EDTA), stained with ethidium bromide, and visualized under UV.

\section{Detection of $\mathrm{H}_{2} \mathrm{O}_{2}$.}

In situ hydrogen peroxide $\left(\mathrm{H}_{2} \mathrm{O}_{2}\right)$ was detected by DAB staining as previously described (Thordal-Christensen et al. 1997). $\mathrm{H}_{2} \mathrm{O}_{2}$ reacts with DAB to form a reddish-brown stain. Inoculated leaf disks were incubated in $\mathrm{DAB}$ solution, $\mathrm{pH} 7.5$, at $1 \mathrm{mg} / \mathrm{ml}$. After incubation in the dark at room temperature for $20 \mathrm{~h}$, samples were boiled in a solution containing alcohol and lactophenol $(2: 1)$ for $5 \mathrm{~min}$ and rinsed twice with $50 \%$ ethanol.

\section{ACKNOWLEDGMENTS}

This work was supported by BARD grants US-3624-04 and US-404107C from the United States-Israel Binational Agricultural Research and Development Fund.

\section{LITERATURE CITED}

Annis, S. L., and Goodwin, P. H. 1997. Recent advances in the molecular genetics of plant cell wall-degrading enzymes produced by plant pathogenic fungi. Eur. J. Plant Pathol. 103:1-14.

Apel, K., and Hirt, H. 2004. Reactive oxygen species: Metabolism, oxidative stress, and signal transduction. Annu. Rev. Plant Biol. 55:373-399.

Baker, C. J., and Mock, N. M. 1994. An improved method for monitoring cell death in cell suspension and leaf disc assays using Evans blue. Plant Cell Tissue Organ Cult. 39:7-12.

Bateman, D. F., and Beer, S. V. 1965. Simultaneous production and synergistic action of oxalic acid and polygalacturonase during pathogenesis by Sclerotiorum rolfsii. Phytopathology 55:204-211.

Berna, A., and Bernier, F. 1999. Regulation by biotic and abiotic stress of a wheat germin gene encoding oxalate oxidase, $\mathrm{a}_{2} \mathrm{O}_{2}$-producing enzyme. Plant Mol. Biol. 39:539-549.

Boland, G. J., and Hall, R. 1994. An index of host plant hosts susceptible to Sclerotinia sclerotiorum. Can. J. Plant Pathol. 16:93-108.

Bolwell, G. P. 1999. Role of active oxygen species and NO in plant defence responses. Curr. Opin. Plant Biol. 2:287-294.

Cessna, S. G., Sears, V. E., Dickman, M. B., and Low, P. S. 2000. Oxalic acid, a pathogenicity factor for Sclerotinia sclerotiorum, suppresses the oxidative burst of the host plant. Plant Cell 12:2191-2200.

Chen, C., Harel, A., Gorovoits, R., Yarden, O., and Dickman, M. B. 2004. MAPK regulation of sclerotial development in Sclerotinia sclerotiorum is linked with $\mathrm{pH}$ and cAMP sensing. Mol. Plant-Microbe Interact. 17:404-413.

Chen, S., and Dickman, M. B. 2004. Bcl-2 family members localize to tobacco chloroplasts and inhibit PCD induced by chloroplast-targeted herbicides. J. Exp. Biol. 55:2617-2623.

Cober, E. R., Rioux, S., Rajcan, I., Donaldson, P. A., and Simmonds, D. H. 2003. Partial resistance to white mold in a transgenic soybean line. Crop Sci. 43:92-95.

Dangl, J. L., and Jones, J. D. 2001. Plant pathogens and integrated defense responses to infection. Nature 411:826-833.

de Bary, A. 1886. Ueber einige Sclerotinien and Sclerotienkrankheiten. Bot. Zeitung 44:377-474.

Dickman, M. B. 2007. Approaches for crop improvement to soilborne fungal diseases through biotechnology: Sclerotinia sclerotiorum as a case study. Australas. Plant Path. 36:116-123.

Dickman, M. B., and Reed, J. C. 2003. Paradigms for programmed cell death in animals and plants. Pages 26-43 in: Programmed Cell Death in Plants. J. Gray, ed. Blackwell, Oxford.

Dickman, M. B., Park, Y. K., Oltersdorf, T., Li, W., Clemente, T., and French, R. 2001. Abrogation of disease development in plants expressing animal antiapoptotic genes. Proc. Natl. Acad. Sci. U.S.A. 98:6957-6962.

Dutton, M. V., and Evans, C. S. 1996. Oxalate production by fungi: Its role in pathogenicity and ecology in the soil environment. Can. J. Microbiol. 42:881-895.

Egan, M. J., Wang, Z. Y., Jones, M. A., Smirnoff, N., and Talbot, N. J. 2007. Generation of reactive oxygen species by fungal NADPH oxidases is required for rice blast disease. Proc. Natl. Acad. Sci. U.S.A. 104:11772-11777.

Filonova, L. H., von Arnold, S., Daniel, G., and Bozhkov, P. V. 2002. Programmed cell death eliminates all but one embryo in a polyembryonic 
plant seed. Cell Death Differ. 9:1057-1062.

Foreman, J., Demidchik, V., Bothwell, J. H., Mylona, P., Miedema, H., Torres, M. A., Linstead, P., Costa, S., Brownlee, C., Jones, J. D., Davies, J. M., and Dolan, L. 2003. Reactive oxygen species produced by NADPH oxidase regulate plant cell growth. Nature 422:442-446.

Fraissinet-Tachet, L., Reymond-Cotton, P., and Fevre, M. 1995. Characterization of a multi-gene family encoding endopolygalacturonase in Sclerotinia sclerotiorum. Curr. Genet. 29:96-99.

Fukuda, H. 2000. Programmed cell death of tracheary elements as a paradigm in plants. Plant Mol. Biol. 44:245-253.

Godoy, G., Steadman, J. R., Dickman, M. B., and Dam, R. 1990. Use of mutants to demonstrate the role of oxalic acid in pathogenicity of Sclerotinia sclerotiorum on Phaseolus vulgaris. Physiol. Mol. Plant Pathol. 37:179-191.

Goodman, R. N., and Novacky, A. J. 1994. The Hypersensitive Reaction in Plants to Pathogens: A Resistance Phenomenon. The American Phytopathological Society, St. Paul, MN, U.S.A.

Govrin, E. M., and Levine, A. 2000. The hypersensitive response facilitates plant infection by the necrotrophic pathogen Botrytis cinerea. Curr. Biol. 10:751-757.

Guimarães, R. L., and Stotz, H. U. 2004. Oxalate production by Sclerotinia sclerotiorum deregulates guard cells during infection. Plant Physiol. 136:3703-3711.

Heath, M. C. 2000. Hypersensitive response-related death. Plant Mol. Biol. 44:321-334

Hengartner, M. O., and Horvitz, H. R. 1994. Activation of Caenorhabditis elegans cell death protein CED-9 by an amino-acid substitution in a domain conserved in Bcl-2. Nature 369:318-320.

Houot, V., Etienne, P., Petitot, A. S., Barbier, S., Blein, J. P., and Suty, L. 2001. Hydrogen peroxide induces programmed cell death features in cultured tobacco BY-2 cells, in a dose-dependent manner. J. Exp. Bot. 52:1721-1730.

Hu, X., Bidney, D. L., Yalpani, N., Duvick, J. P., Crasta, O., Folkerts, O., and Lu, G. 2003. Overexpression of a gene encoding hydrogen peroxide-generating oxalate oxidase evokes defense responses in sunflowers. Plant Physiol. 133:170-181.

Hurkman, W. J., Lane, B. G., and Tanaka, C. K. 1994. Nucleotide sequence of a transcript encoding a germin-like protein that is present in saltstressed barley (Hordeum vulgare L.) roots. Plant Physiol. 104:803-804.

Jabs, T. 1999. Reactive oxygen intermediates as mediators of programmed cell death in plants and animals. Biochem. Pharmacol. 57:231-245.

Jabs, T., Dietrich, R. A., and Dangl, J. L. 1996. Initiation of runaway cell death in an Arabidopsis mutant by extracellular superoxide. Science 273:1853-1856.

Lane, B. G., Dunwell, J. M., Ray, J. A., Schmitt, M. R., and Cuming, A. C. 1993. Germin: A protein marker of early plant development is an oxalate oxidase. J. Biol. Chem. 268:12239-12242.

Legendre, L., Rueter, S., Heinstein, P. F., and Low, P. S. 1993. Characterization of the oligogalacturonide-induced oxidative burst in cultured soybean (Glycine max) cells. Plant Physiol. 102:233-240.

Leuthner, B., Aichinger, C., Oehmen, E., Koopmann, E., Muller, O., Muller, P., Kahmann, R., Bolker, M., and Schreier, P. H. 2005. A $\mathrm{H}_{2} \mathrm{O}_{2}$ producing glyoxal oxidase is required for filamentous growth and pathogenicity in Ustilago maydis. Mol. Genet. Genomics 272:639-650.

Lim, P. O., Kim, H. J., and Nam, H. G. 2007. Leaf senescence. Annu. Rev. Plant Biol. 58:115-136.

Lumsden, R. D. 1979. Histology and physiology of pathogenesis in plant diseases caused by Sclerotinia species. Phytopathology 69:890-896.

Marciano, P., Di Lenna, P., and Magro, P. 1983. Oxalic acid, cell wall degrading enzymes and $\mathrm{pH}$ in pathogenesis and their significance in the virulence of two Sclerotinia sclerotiorum isolates on sunflower. Physiol. Plant Pathol. 22:339-345.

Nakazato, T., Sagawa, M., Yamato, K., Xian, M., Yamamoto, T., Suematsu, M., Ikeda, Y., and Kizaki, M. 2007. Myeloperoxidase is a key regulator of oxidative stress mediated apoptosis in myeloid leukemic cells. Clin. Cancer Res. 13:5436-5445.

Nathues, E., Joshi, S., Tenberge, K. B., von den Driesch, M., Oeser, B., Baumer, N., Mihlan, M., and Tudzynski, P. 2004. CPTF1, a CREB-like transcription factor, is involved in the oxidative stress response in the phytopathogen Claviceps purpurea and modulates ROS level in its host Secale cereale. Mol. Plant-Microbe Interact. 17:383-393.

Navarre, D. A., and Wolpert, T. J. 1999. Victorin induction of an apoptotic/senescence-like response in oats. Plant Cell 11:237-249.

Noyes, R. D., and Hancock, J. G. 1981.Role of oxalic acid in the Sclerotinia wilt of sunflower. Physiol. Plant Pathol. 18:123-132.

Pennell, R. I., and Lamb, C. 1997. Programmed cell death in plants. Plant Cell 9:1157-1168.

Riou, C., Freyssinet, G., and Fevre, M. 1991. Production of cell wall degrading enzymes by the phytopathogenic fungus Sclerotinia sclerotiorum. Appl. Environ. Microbiol. 57:1478-1484.

Rolke, Y., Liu, S., Quidde, T., Williamson, B., Schouten, A., Weltring, K.M., Siewers, V., Tenberge, K. B., Tudzynski, B., and Tudzynski, P. 2004. Functional analysis of $\mathrm{H}_{2} \mathrm{O}_{2}$-generating systems in Botrytis cinerea: The major $\mathrm{Cu}-\mathrm{Zn}$-superoxide dismutase (BCSOD1) contributes to virulence on French bean, whereas a glucose oxidase (BCGOD1) is dispensable. Mol. Plant Pathol. 5:17-27.

Rollins, J. A., and Dickman, M. B. 2001. pH signaling in Sclerotinia sclerotiorum: Identification of a pacC/RIM1 homolog. Appl. Environ. Microbiol. 67:75-81.

Ryerson, D. E., and Heath, M. C. 1996. Cleavage of nuclear DNA into oligonucleosomal fragments during cell death induced by fungal infection or by abiotic treatments. Plant Cell 8:393-402.

Samuilov, V. D., Lagunova, E. M., Dzyubinskaya, E. V., Izyumov, D. S., Kiselevsky, D. B., and Makarova, Y. V. 2002. Involvement of chloroplasts in the programmed death of plant cells. Biochemistry 67:627634.

Samuilov, V. D., Lagunova, E. M., Gostimsky, S. A., Timofeev, K. N., and Gusev, M. V. 2003. Role of chloroplast photosystems II and I in apoptosis of pea guard cells. Biochemistry 68:912-917.

Steadman, J. R. 1979. Control of plant diseases caused by Sclerotinia species. Phytopathology 69:904-907.

Tada, Y., Hata, S., Takata, Y., Nakayashiki, H., Tosa, Y., and Mayama, S. 2001. Induction and signaling of an apoptotic response typified by DNA laddering in the defense response of oats to infection and elicitors. Mol. Plant-Microbe Interact. 14:477-486.

Tanaka, A., Christensen, M. J., Takemoto, D., Park, P., and Scott, B. 2006. Reactive oxygen species play a role in regulating a fungus-perennial ryegrass mutualistic interaction. Plant Cell 18:1052-1066.

Thordal-Christensen, H., Zhang, Z., Wei, Y., and Collinge, D. B. 1997. Subcellular localization of $\mathrm{H}_{2} \mathrm{O}_{2}$ in plants. $\mathrm{H}_{2} \mathrm{O}_{2}$ accumulation in papillae and hypersensitive response during the barley-powdery mildew interaction. Plant J. 11:1187-1194.

Torres, M. A., Onouchi, H., Hamada, S., Machida, C., Hammond-Kosack, K. E., and Jones, J. D. 1998. Six Arabidopsis thaliana homologues of the human respiratory burst oxidase (gp91phox). Plant J. 14:365-370.

Tourneau, D. L. 1979. Morphology, cytology, and physiology of Sclerotinia species in culture. Phytopathology 69:887-890.

Turner, S., Gallois, P., and Brown, D. 2007. Tracheary element differentiation. Annu. Rev. Plant Biol. 58:407-433.

Unger, Ch., Kleta, S., Jandl, G., and von Tiedemann, A. 2005. Suppression of the defense-related oxidative burst in bean leaf tissue and bean suspension cells by the necrotrophic pathogen Botrytis cinerea. J. Phytopathol. 153:15-26.

Van Baarlen, P., Staats, M., and Van Kan, J. A. L. 2004. Induction of programmed cell death in lily by the fungal pathogen Botrytis elliptica. Mol. Plant Pathol. 5:559-574.

Vaux, D. L., and Strasser, A. 1996. The molecular biology of apoptosis. Proc. Natl. Acad. Sci. U.S.A. 93:2239-2244.

Wang, W., Jones, C., Ciacci-Zanella, J., Holt, T., Gilchrist, D. G., and Dickman, M. B. 1996. Fumonisins and Alternaria alternata lycopersici toxins: Sphinganine analog mycotoxins induce apoptosis in monkey kidney cells. Proc. Natl. Acad. Sci. U.S.A. 93:3461-3465.

Yao, N., Tada, Y., Park, P., Nakayashiki, H., Tosa, Y., and Mayama, S. 2001. Novel evidence for apoptotic cell response and differential signals in chromatin condensation and DNA cleavage in victorin-treated oats. Plant J. 28:13-26. 